\section{CAUSE FOR APPLAUSE}

Henry's Angels, a team of employees from Henry Schein UK, overhauled a large patch of garden earlier this year for EllenorLions Hospice in Gravesend, an organisation that cares for adults with life-limiting illnesses and its children's hospice chYps. The team have since completed nine charitable projects involving over 2,000 hours of work.

Dr Angel Ashtalkoski, a dentist at Smiles Dental in Tallaght, Dublin, volunteered his time and skills to help provide dental care to the underprivileged residents of Haiti, supported by Smiles Dental/JHA. Dr Ashtalkoski mainly worked with disabled children living at the L'oeuvre St François D'assises orphanage on the Island of île à Vache off the south coast of Haiti.

GSK has formed a collaboration with Save the Children to share expertise, resources, reach and influence to tackle some of the leading causes of childhood deaths. Amongst the key initiatives are the transformation of an antiseptic used in mouthwash into a life-saving product for newborns and the roll-out of a powder form of an antibiotic in child friendly doses to help fight pneumonia one of the main killers of children under five.

The 8th annual free Mouth Cancer Foundation 10 km Awareness Walk takes place on 29 September 2013 in Hyde Park, London. To sign up visit www. mouthcancerwalk.org.

The Straumann Charity Bike Ride 2013 takes place on 19-24 September 2013, starting at the Straumann headquarters in Basel, Switzerland and finishing at the Head Office of Straumann UK in Crawley, West Sussex. Thirty people are preparing to cycle the 600 miles in six days aiming to raise over $€ 30,000$ for Bridge2Aid and the Cleft Lip \& Palate Association (CLAPA).

Dental Design has pledged to donate $€ 1$ for every new 'like' on Facebook or new follower on Twitter throughout July to dental charity Bridge2Aid. Dental Design has been supporting Bridge2Aid's online marketing and spreading news of the charity's work. facebook.com/dentaldesignltd

Dr Ross Cutts, a dentist from Cirencester, is aiming to raise $£ 18,000$ for Breast Cancer Care by competing in 18 challenging sporting events over 18 months, including the Straumann Bike Ride mentioned above.

Participants in the Dentaid Golf Day 2013 raised over $€ 2,300$ in June which will be used to sponsor a DentaidBox, a portable dental surgery in a wheelie bin that enables oral health workers to provide vital, pain relieving dental care to many people in disadvantaged communities.

Dr Hedley Saunders, an Exmouth dentist, has been honoured with a silver statuette by the Royal National Lifeboat Institution (RNLI). Dr Saunders has raised thousands of pounds for the charity and is also a volunteer tractor driver to launch and recover the lifeboat from Exmouth beach.

\section{FIFTY PRACTICES ADDRESS CARIES MANAGEMENT}

Over 250 dental professionals from 50 UK dental practices are undertaking a study addressing how best to deal with caries in young children's teeth.

'Filling Children's Teeth:

Indicated or Not?' - or FiCTION - is a study funded by the National Institute for Health Research's Health Technology Assessment Programme and will inform the debate around managing caries in the primary dentition by providing robust evidence.

The study is investigating three approaches to managing caries in the primary teeth of 3-7-yearolds: 1) the conventional approach with prevention - fully removing caries using local anaesthesia and conventional restorations;

2) the biological approach with prevention - caries is either left in situ or only partially removed before being sealed off from the oral environment using adhesive restorations or preformed metal crowns; and finally 3) the prevention alone approach - arresting dental caries by application of intensive preventive techniques according to national guidelines.

The dental practices taking part in the study are volunteers from Cardiff, London, North-East England, Scotland, Yorkshire and Derbyshire, making FiCTION one of the biggest clinical studies ever to take place in primary dental care in the UK. Regular regional meetings are being held to bring the individual practices together to discuss the progress of the trial and to share experiences.

More information on the FiCTION Trial can be found at http://research.ncl.ac.uk/fictiontrial/ or you can email the Trial Administrator, Amy CaldwellNichols, at fiction@dundee.ac.uk.

\title{
HEARTBURN INCREASES MOUTH CANCER RISK
}

A new study has identified that heartburn almost doubles the risk of developing mouth cancer. ${ }^{1}$

Researchers at Brown University in the US studied 631 patients with mouth cancer and 1,234 control subjects. They discovered that participants with frequent heartburn who were neither heavy smokers nor heavy drinkers had a 78\% increased risk of developing mouth cancer. They also discovered that taking indigestion tablets had a preventive effect among those who had frequent heartburn. According to the research, those people had a $41 \%$ reduced risk of cancer of the throat and vocal cord.

1. Langevin S M, Michaud D S, Marsit C J et al. Gastric reflux is an independent risk factor for laryngopharyngeal carcinoma. Cancer Epidemiol Biomarkers Prev 2013; 22: 1005

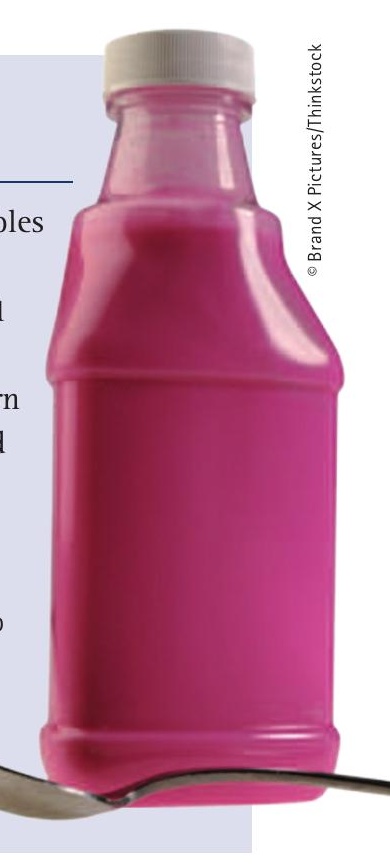

\section{RESEARCH INTO ORAL BACTERIA AND FOETAL DEATH}

A four-year, \$1.58 million grant from the National Institute of Dental and Craniofacial Research will allow a Case Western Reserve University School of Dental Medicine researcher to advance her work linking oral bacteria to foetal death.

The grant will support a study by Yiping Han, professor of periodontics, that focuses on the prevalent oral bacteria, Fusobacterium, and several of its subspecies. The bacteria keep the mouth's natural disease defences working, but can also cause diseases when they enter the bloodstream. 